\title{
The Efficacy of Flavonoid Antioxidant from Chocolate Bean Extract: Prevention of Myocyte Damage Caused by Reperfusion Injury in Predominantly Anaerobic Sports
}

\author{
HN Rasyid, MS Orth, YD Ismiarto, MS Orth, R Prasetia, MS Orth \\ Department of Orthopaedics and Traumatology, Faculty of Medicine Universitas Padjadjaran / Hasan Sadikin \\ General Hospital, Bandung, Indonesia
}

\begin{abstract}
Background: Use of predominantly anaerobic energy systems such as that seen in 800-meter athlete runners disrupts mitochondrial function as an energy source. Furthermore, it produces free radical substances and causes myocyte damage. Malondialdehyde (MDA) plasma concentrations correlate with free radical levels and are therefore predictive of cell damage. Objective: To analyse the effect of flavonoid antioxidant from chocolate bean extract for prevention of lipid peroxidation of myocyte membranes caused by free radical substances in athletes partaking in predominantly anaerobic sports. Materials and Methods: The study of population consisted of 16 junior athletes who compete in 800-meter races. This was a randomized experimental study. Subjects were divided into two groups, chocolate bean extracts and placebo groups, and then practiced regularly for 14 days. All subjects were assessed on day 15 . Results were analysed statistically using paired $t$ test, ANOVA and Duncan tests. Results: Concentrations of MDA were reduced in flavonoid group. Conclusion: Flavonoid antioxidant from chocolate bean extract may prevent myocyte damage was caused by reperfusion injury.
\end{abstract}

Key Words:

Chocolate bean extract, Flavonoid, Malondialdehyde

\section{INTRODUCTION}

The athlete who runs a distance of 800-meters is considered a middle distance runner. Energy systems for this sport comprises aerobic and anaerobic systems. The predominant energy system used is the lactic anaerobic energy system ${ }^{1}$. When athletes compete, practice, or participate in other activities with high intensity under anaerobic conditions, athletes will produce large quantities of free radicals ${ }^{2}$.

Myocytes actively experience ischemic condition during muscle contraction, meaning that xanthine substances produced from adenosine triphosphate (ATP) and xanthine dehydrogenase $(\mathrm{XD})$ will be altered to xanthine oxide (XO). When muscles relax, myocytes undergo reperfusion, causing a sudden and rapid oxygen concentration increase; at these times, XO continues to transform hypoxanthine to uric acid with oxygen molecules as electron acceptors ${ }^{2-5}$, eventually producing high quantity of free radicals ${ }^{3}$.

Free radicals on myocyte sarcoplasm will disrupt energy and can even destroy the mitochondrial lipid membrane, resulting in functional inability of mitochondria. This enables the myocytes to maintain cell membrane integrity and intracellular metabolism. These circumstances cause possible myocyte damage that is the upstream reason for decline in athletic achievement at longer distances.

One of the efforts to improve achievements in these athletes involves supplemental nutrition aimed at prevention of myocyte damage caused by free radicals. There are several experiments that prove the safety and efficacy of such supplements (a variety of antioxidant substances such as flavonoid found in chocolate bean (Theobroma Cacao) extract). We assumed such effects correlate with efficacy of the energy producing system ${ }^{6}$. Chocolate beans containing polyphenol substances contain high levels of flavonoid antioxidants ${ }^{7}$. Flavonoid as an antioxidant becomes a free radical scavenger by releasing one electron from its hydroxyl site.

Free radical level calculation in 800-meter distance runners is fraught with error as it is reactive and levels change quickly ${ }^{8,9}$. Detection of the end product of free radical chain reaction is an alternative approach (i.e., analysis of malondialdehyde (MDA) levels and is predictive of free radical concentration ${ }^{10,11}$.

The aim of this study was to analyse the effect of flavonoid antioxidants from chocolate bean extract for prevention of lipid peroxidation of myocytes membrane caused by free radical substances in predominantly anaerobic sports. 


\section{MATERIALS AND METHODS}

The research was carried out on 16 athletes, based on sample calculating formulation that was randomized in simple sampling. Inclusion criteria were: male; age range 19-23 years; 800-meter distance runners; in good health; and without acute or chronic illness. Exclusion criteria were: high intensity activity in the 24-hours before the study; or consumption of any supplement or nutrition that influenced antioxidant concentration within the previous seven days. The study was approved by the Health Research Ethics Committee of Faculty of Medicine Universitas Padjadjaran, Bandung, Indonesia. All participants gave written informed consent to participate in this study.

Subjects were randomized into two groups. Group-A consisted of eight runners who were treated chocolate bean extract (labelled as chocolate bean extract group) ; Group-B consisted of eight runners as control group with administration of placebo (called placebo group).

Weight and height were measured in all subjects, that was followed by a 15-minute warm-up period. Next followed 14 days of administration of a $500 \mathrm{mg} /$ capsule of chocolate bean extract twice a day before meals for Group A, and administration of a placebo (saccharine) capsule twice a day before meals for Group B. Then the athletes ran 800 meters, and submitted to post-run blood sample collection to ascertain MDA plasma levels. On day 15 , all subjects were weighed and measured again.

Thiobarbituric Acid Reactive Substance (TBARS) levels were assayed to calculate free radical concentrations. Spectrophotometry was used to assess chromogenes resulting from reaction between thiobarbituric acid and MDA. This reaction would create pink colour during warmup sessions ${ }^{3}$.

\section{Statistical Analysis}

Statistical analyses were performed for homogeneity (Levene's test; $p \geq 0,05$ ) and normality (Kolmogrov Smirnov; $p \geq 0,05$ ). Further, the results were analysed statistically by paired $t$ test, ANOVA and Duncan tests.

\section{RESULTS}

We recorded physical characteristics for both groups such as: age (years), weight $(\mathrm{kg})$, height $(\mathrm{cm})$, Body Mass Index /BMI $\left(\mathrm{kg} / \mathrm{m}^{2}\right)$, and systolic and diastolic pressure $(\mathrm{mmHg})$. Based on Levene's homogeneity test, the data from both groups were homogeneous $(p>0.05)$, and based on the Kolmogorov-Smirnov normality test the data from both groups were normally distributed $(p>0.05)$. These data are presented in Table I.

Next, we performed statistical analyses to compare the efficacy of chocolate bean extract with the concentration of
MDA plasma levels. Differences were analysed for significance using paired $t$ test, with significance assumed at $\mathrm{p}$-values $<0.05$. MDA plasma levels after consuming chocolate bean extract were lower than before such consumption $(225.9 \pm 65.4$ vs. $55.47 \pm 14.11 \mathrm{nmol} / \mu \mathrm{L}$ $(\mathrm{p}=0.000))$, demonstrating that this intervention was efficacious in reducing the MDA plasma levels on these athletes (who participate in anaerobic metabolism sports). Results are presented in Table II.

ANOVA was performed to evaluate the differences between chocolate bean extract and placebo in reducing MDA plasma levels. Administration of chocolate bean significantly differed from placebo in its capacity to reduce MDA plasma concentrations $(p<0.05)$. Results also demonstrated that chocolate bean extract reduced concentrations of MDA in plasma at a rate $8.65 \%$ higher than placebo $(170.430 \mathrm{vs}$. $150.70 \mathrm{nmol} / \mu \mathrm{L}$ ). The effects of both interventions following an 800 meter run are presented in Fig. 1 and Table II.

\section{DISCUSSION}

The results of this study showed that the plasma MDA levels were lower after consuming chocolate bean extract than before consumption according to paired $\mathrm{t}$ test results $(225.9 \pm 65.4$ vs. $55.47 \pm 14.11 \mathrm{nmol} / \mu \mathrm{L} ; \mathrm{p}<0.05)$. ANOVA showed that there were differences between chocolate bean extract and placebo in reducing the plasma MDA levels $(\mathrm{p}<$ 0.05 ). There were also different effects between chocolate bean extract and placebo in reducing concentrations of MDA in plasma following participation in predominantly anaerobic sports. Based on Duncan's test, the chocolate bean extract reduced MDA plasma concentrations at a rate $8.65 \%$ higher than placebo (170.430 vs. $150.70 \mathrm{nmol} / \mu \mathrm{L})$.

Chocolate bean extract contains polyphenol substances ${ }^{4}$, and high levels of flavonoid antioxidant substances. Flavonoids have antioxidant effects at the intracellular or extracellular antioxidant substances levels. Inhibition of XO enzyme activity is a free radical defence mechanism that has as its purpose conversion of XO produced by ischemic reperfusion to XD so that free radical substance production decreases ${ }^{3-6}$. Radical scavenging is a free radical defence mechanism that has as its purpose to 'catch' free radicals via an inhibitory initiation of a chain reaction and chopping propagation free radical reaction. The mechanism through which this occurs includes donating one free hydrogen atom to stabilize free radical substances ${ }^{12}$. Transition metal chelation is a free radical defence mechanism in which there is a reaction with transition metal that is important in the production of free radical substances such as, cuprum, ferrum, zincum ${ }^{12}$. Flavonoid inhibits pro-oxidant enzymes such as, nitric acid synthetase, lipoxygenases, and cyclooxygenase, which have as their purpose inhibition of lipopolysaccharide that induces gene expression from iNOS (intracellular Nitric Oxide Synthetase) and inhibition of iNOS activity on 
Table I: Physical Characteristic of athletes participating in 800-Meter runs

\begin{tabular}{|c|c|c|c|c|c|}
\hline Variables & Group & $\mathbf{N}$ & $\bar{\chi}$ & SD & $\mathbf{P}$ \\
\hline \multirow[t]{2}{*}{ Age (years) } & Chocolate bean extract & 8 & 20.25 & 1.28 & 0.161 \\
\hline & Control & 8 & 20.50 & 1.41 & \\
\hline \multirow[t]{2}{*}{ Weight (Kg) } & Chocolate bean extract & 8 & 57.13 & 5.74 & 0.735 \\
\hline & Control & 8 & 57.63 & 7.35 & \\
\hline \multirow[t]{2}{*}{ Height $(\mathrm{Cm})$} & Chocolate bean extract & 8 & 167.88 & 6.27 & 0.360 \\
\hline & Control & 8 & 170.75 & 6.07 & \\
\hline \multirow[t]{2}{*}{ BMI (Kg/m2) } & Chocolate bean extract & 8 & 20.50 & 2.00 & 0.768 \\
\hline & Control & 8 & 19.75 & 1.67 & \\
\hline \multirow[t]{2}{*}{ Systole $(\mathrm{mmHg})$} & Chocolate bean extract & 8 & 117.50 & 7.07 & 0.636 \\
\hline & Control & 8 & 118.75 & 8.35 & \\
\hline \multirow[t]{2}{*}{ Diastole $(\mathrm{mmHg})$} & Chocolate bean extract & 8 & 75.00 & 7.56 & 0.508 \\
\hline & Control & 8 & 78.75 & 6.41 & \\
\hline
\end{tabular}

Note : $p>0.05$ represents a statistically insignificant difference between two groups

Table II: MDA Plasma Concentration in athletes participating in 800-meter races - Effect of Chocolate Bean (Theobroma Cacao) Extract vs. Placebo

\begin{tabular}{|lcccc|}
\hline MDA & $\mathbf{( n m o l} / \mathbf{\mu L})$ & Treatment & F-test & P-value \\
\hline Pre test & $225.90(65.48)$ & $231.07(37.37)$ & 1.910 & 0.173 \\
Post test & $55.47(14.11)$ & $80.38(26.59)$ & 4.025 & 0.033 \\
t-paired & -7.704 & -11.880 & & \\
P-value & 0.000 & 0.000 & & 0.048 \\
Pre and post test differences & -170.43 & -150.70 & 3.534 & 0.019 \\
Decreasing value & 73.83 & 65.18 & 4.790 & \\
\hline
\end{tabular}

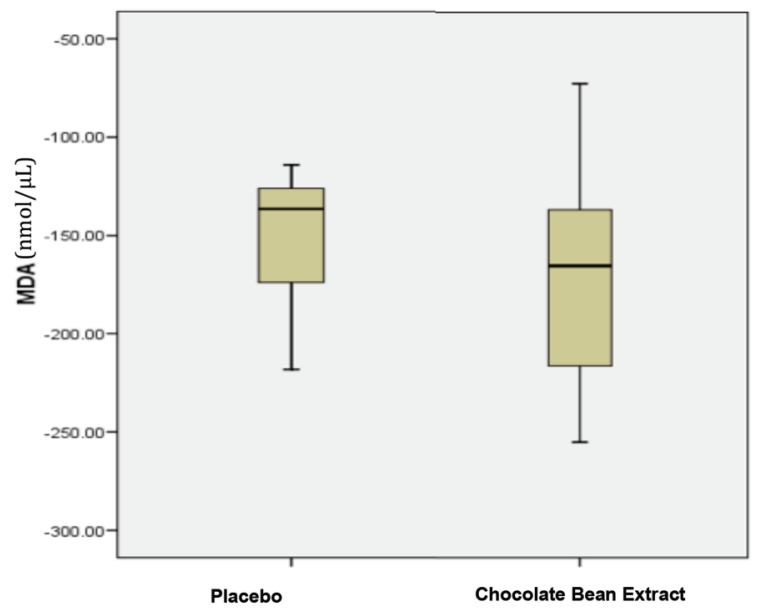

Fig. 1: Plasma Concentration of MDA in athletes running 800Meter distance - Difference between effects of Chocolate Bean and Placebo.

macrophages ${ }^{13}$. Leucocyte immobilization is a free radical defence mechanism for inhibition of neutrophil degranulation so that oxidative damage can be prevented ${ }^{14}$.
Based on our results, the concentration of MDA in plasma declines in the control group in relation to increasing endogenous antioxidant production that is caused by an adaptation mechanism in athletes. These circumstances are concordant with previous studies which reported that regular aerobic or anaerobic exercise alters the body antioxidant concentration and that this is caused by compensatory mechanisms to oxidative stresses ${ }^{15,16}$.

\section{CONCLUSION}

The current study on the 800-meter distance athletes (in predominantly anaerobic sports) demonstrates the effectiveness of chocolate bean (Theobroma cacao) in prevention of lipid peroxidation of myocyte membranes caused by free radical substances.

\section{ACKNOWLEDGMENTS}

We thank the Dean of the Faculty of Medicine Universitas Padjadjaran, and the Director of Hasan Sadikin General Hospital, Bandung, Indonesia for their support and encouragement. Special thanks to all subjects of 800 - meter distance junior athletes from West Java for their participation in this research. 


\section{REFERENCES}

1. Foss ML, Keteyian SJ. Fox's physiological basis for exercise and sport. 6th ed., Boston, MA: McGraw-Hill; 1998, pp31-40.

2. Papas AM. Antioxidant status, diet, nutrition and health. CRC Press LLC, Boca Raton, FL, 1999. pp. 21-36.

3. Deaton CM, Marlin DJ. Exercise associated oxidative stress. Clinical Tech Equine Pract. 2003; 189(1): 278-91.

4. Whitney E, Rolfes SR. Energy balance and body composition. Howe E, Fieldman E, eds., Understanding nutrition, 10th ed., Belmont, CA: Thomson Wadsworth, 2005. pp. 250-71.

5. Serafini M, Bugianesi R, Malani G, Valtuena S, De Santis S, Crozier A. Plasma antioxidant from chocolate. Nature. 2003; 426: $787-8$.

6. Lazarus SA, Hammerstone JF, Schmitz HA. Chocolate contains additional flavonoids not found in tea. Lancet. 1999; 354: 18258.

7. Engler MB, Chen CY, Malloy MJ, Browne A, Elisa BS. Flavonoid-rich dark chocolate improves endothelial function and increase plasma epicatechin concentration. J Am Coll Nutr. 2004; 23(3): 197-204.

8. Mayne ST. Antioxidant nutrients and chronic disease: Use of biomarkers of exposure and oxidative stress status in epidemiologic research. J. Nutrition . 2003; 133: 933-40.

9. Collins A. Assays for oxidative stress and antioxidative status: applications to research into the biological effectiveness of polyphenols. Am J Clin Nutr. 2005; 81(1): 261-7.

10. Nielsen F, Mikkelsen B, Nielsen J. Plasma malondialdehyde as biomarkers for oxidative stress: reference interval and effects of life style factors. Am. Assoc. Clin. Chemistry. 1997; 7: 1209-14.

11. Snell P. Middle distance running. In: Physiology of sport. London: E and FN SPON; 1993. pp. 173-213.

12. Kumar V, Abbas AK, Fausto N, editors. Robbins and cotran pathologic basis of disease. 7th ed. Philadelphia: Saunders Elsevier; 2005. pp. 564-6.

13. Nijveldt RJ, van Nood E, van Hoorn DE, Boelens PG, van Norren K, van Leeuwen PA. Flavonoids: a review of probable mechanisms of action and potential applications. Am J Clin Nutr. 2001; 74(4): 418-25.

14. Shoskes DA. Effect of bioflavonoids quercetin and curcumin on ischemic renal injury: A new class of renoprotective agents. Transplantation. 1998; 66: 147-52.

15. Qiau D, Hou L, Liu X. Influence of intermittent anaerobic exercise on mouse physical endurance and antioxidant components. Br J Sport Medicine. 2005; 40(3): 214-8.

16. Valado A, Pereira L, Tavares PC, Ribeiro CF. Effect of the intense anaerobic exercise on nitric oxide and malondialdehyde in studies of oxidative stress. Int. J. Biology and Biomedical Engineering. 2007; 1: 32-6. 